\title{
Cardiovascular disease and cancer associated with neurological problems: Some hope for innovative combinatorial approaches
}

\author{
Guertin PA* \\ Department of Psychiatry and Neurosciences, Laval University Medical Center - CHU de Quebec, Canada
}

\begin{abstract}
Cardiovascular disease (CVD) caused secondarily by spinal cord injury, multiple sclerosis or other types of neurological problems impairing mobility can be lifethreatening. Recovery of mobility and muscular function, even temporarily, could prevent or reverse CVD in people with mobility impairment or paralysis. However, attempts at developing therapeutic approaches capable of repairing spinal cord injury or multiple sclerosis have generally remained inconclusive. This said, promising clinical data have recently revealed that paralysis and mobility impairment after neurological trauma could soon become treatable. Indeed, a drug treatment called Spinalon was reported in complete or motor-complete spinal cord-injured individuals to induce locomotor-like activity in both legs. Other approaches, using electrical stimulation, have also shown that locomotor-like contractions can be induced on-demand in paralyzed people. Although full recovery of even basic walking movement voluntarily initiated or 'reflexively' induced has not yet been achieved by scientists, new hope has emerged from these pharmacological and electrical approaches either used separately or as combination therapies.
\end{abstract}

\section{Editorial}

Spinal cord injury (SCI) of traumatic origin affects $1.3 \mathrm{M}$ people in the U.S. [1]. Although global prevalence has not been systemically assessed yet, this could represent as many as $28 \mathrm{M}$ patients currently suffering a traumatic SCI worldwide [2]. The global prevalence of non-traumatic SCI such as multiple sclerosis remains unknown. The World Health Organization (WHO) reports that $17.5 \mathrm{M}$ people die each year from cardiovascular disease (CVD) - that is $31 \%$ of all deaths worldwide [3]. Cancer is almost equally devastating with $8.2 \mathrm{M}$ patients dying each year [4]. Based on data from the U.K., about $50 \%$ of all individuals with cancer having received proper treatments survive to the disease for at least ten years [5]. Unfortunately, increasing evidence from epidemiologists suggests that a significant proportion of cancer survivors will, within months or years post-treatment, suffer or even die instead of CVD directly attributable to the chemotherapy and/or radiotherapy [6]. This relatively new pathological condition (cancer therapy-induced CVD) has first been revealed nearly fifty years ago with anthracyclines - they are antibiotics derived from Streptomyces that have been widely used as chemotherapy since the late 60s against leukemia, lymphoma, breast, stomach, uterine, ovarian, bladder and lung cancer [6]. Their dose-dependent cardiotoxicity has also been detected back then with asymptomatic myocardial dysfunction, originally detected in children, ranging between 18 and $57 \%$ of the survivors - $5 \%$ die of heart failure $[7,8]$. CVD displays also greater incidence in people with SCI than in the general population [9]. Obviously, in the case of SCI, it is not chemotherapy-induced but reduced mobility/ paralysis associated with a lack of metabolicallychallenging physical activity that causes secondarily the development of CVD. Moreover, chronic SCI has also been associated with greater incidence of some cancer (e.g., bladder, esophageal, liver and hematologic cancer) $[10,11]$. Physical activity has been shown to prevent and mitigate cardiotoxicity related to anthracycline therapy whereas a lack of physical activity due to paralysis after SCI increases the prevalence of chronic comorbid diseases including cancer $[12,13]$. In other words, therapeutic approaches aimed at restoring or improving regular metabolically-challenging physical activity in patients with SCI shall contribute to reduce the incidence or severity of chronic diseases including CVD and cancer $[13,14]$. Recent evidence suggests that a drug candidate called Spinalon may be capable of eliciting spinal locomotor neuron activity and, hence, corresponding episodes of involuntary walking on a treadmill in completely paralyzed mice and humans $[14,15]$. Transdermal electric stimulation has also recently been found to elicit on-demand locomotor-like movements in humans [16]. To further reduce CVD, cardio-protective drug such as dexrazoxane (FDA approved) or statins (not yet specifically approved by FDA), could thus probably be used concomitantly with Spinaloninduced locomotor exercising [17] assisted by electrical stimulation. In conclusion, it may be that regular metabolically challenging training on a treadmill enabled by these approaches (i.e., Spinalon, cardio-protective drugs, transdermal stimulation) used separately or combined could yield cardiovascular benefits and reduced incidence of some cancers in people suffering of SCI or related neurological problems such as multiple sclerosis.

\section{References}

1. Foundation CaDR (2010) One degree of separation: paralysis and spinal cord injury in the United States.

Correspondence to: Pierre A Guertin, Department of Psychiatry and Neurosciences, Laval University Medical Center - CHU de Quebec, Canada, E-mail: pierre.guertin@crchul.ulaval.ca

Received: February 10, 2017; Accepted: March 14, 2017; Published: March 16, 2017 
2. Singh A, Tetrault L, Kalsi-Ryan S, Nouri A, Fehlings MG (2014) Global prevalence and incidence of traumatic spinal cord injury. Clin Epidemiol 6: 209-331.

3. 22 September, 2016: "Global Hearts", a new initiative from the World Health Organization (WHO). New initiative launched to tackle cardiovascular disease, the world's number one killer. Cardiovascular disease. http://www.who.int/cardiovascular_ diseases/en/

4. WHO Media centre (2017) Cancer. http://www.who.int/mediacentre/factsheets/fs297/en/

5. http://www.cancerresearchuk.org/

6. Fujiwara A, Hoshino T, Westley JM (1985) Anthracycline antibiotics. Critical Reviews in Biotechnology. Anthracycline 3: 133.

7. Mele D, Nardozza M, Spallarossa P, Frassoldati A, Tocchetti CG, et al. (2016) Current views on anthracycline cardiotoxicity. Heart Fail Rev 21: 621-34.

8. Kucharska W, Negrusz-kawecka M, Gromkowska M (2012) Cardiotoxicity of oncological treatment in children. Adv Clin Exp Med 21: 281-288.

9. Hagen EM, Rekand T, Gronning M, Faerestrand S (2012) Cardiovascular complications of spinal cord injury. Tidsskr Nor Laegeforen 132: 1115-1120.

10. Kalisvaart JF, Katsumi HK, Ronningen LD, Hovey RM (2010) Bladder cancer in spinal cord injury patients. Spinal Cord 48: 257-261.

11. Kao CH, Sun LM, Chen YS, Lin CL, Weng MW (2016) Risk of Nongenitourinary
Cancers in Patients With Spinal Cord Injury - A Population-based Cohort Study. Medicine 95: e2462.

12. Chen JJ, Wu PT, Middlekauff HR, Nguyen KL (2016) Aerobic Exercise in Anthracycline-Induced Cardiotoxicity: A Systematic Review of Current Evidence and Future Directions. Am J Physiol Heart Circ Physiol Dec 6: ahead of print.

13. Smith AE, Molton IR, Jensen MP (2016) Self-reported incidence and age of onset of chronic comorbid medical conditions in adults aging with long-term physical disability. Disabil Health J 9: 533-538.

14. Guertin PA, Ung RV, Rouleau P, Steuer I (2011) Effects on locomotion, muscle, bone, and blood induced by a combination therapy eliciting weight-bearing stepping in nonassisted spinal cord-transected mice. Neurorehabil Neural Repair 25: 234-242.

15. Radhakrishna M, Steuer I, Prince F, Roberts M, Mongeon D, et al. (2016) Double-blind, placebo-controlled, randomized phase I/IIa study (safety and efficacy) with buspirone/ levodopa/carbidopa (Spinalon) in subjects with complete AIS A or motor-complete AIS B spinal cord injury. Curr Pharm Des Dec 27. Ahead of print.

16. Hofstoetter US, Knikou M, Guertin PA, Minassian K (2016) Probing the Human Spinal Locomotor Circuits by Phasic Step-Induced Feedback and by Tonic Electrical and Pharmacological Neuromodulation. Curr Pharm Des Dec 27. Ahead of print.

17. Henninger C, Fritz G (2017) Statins in anthracycline-induced cardiotoxicity: Rac and Rho, and the heartbreakers. Cell Death Dis 8: e2564.

Copyright: $(02017$ Guertin PA. This is an open-access article distributed under the terms of the Creative Commons Attribution License, which permits unrestricted use, distribution, and reproduction in any medium, provided the original author and source are credited. 